\title{
On the Dynamic Performance of Flax Fiber Composite Beams Manufactured at Different Relative Humidity Levels
}

\author{
Huaizhong Li (1) ${ }^{a}$, Abdul Moudood ${ }^{a}$, Wayne Halla, Gaston Francuccib, and Andreas Öchsner ${ }^{\mathrm{a}}$ \\ aSchool of Engineering and Built Environment, Gold Coast Campus, Griffith University, Southport, QLD, Australia; \\ ${ }^{b}$ Research Institute of Material Science and Technology (INTEMA-CONICET), National University of Mar del Plata, Mar \\ del Plata, Argentina
}

\begin{abstract}
Development of environment-friendly natural fiber composites has been a recent trend. However, due to the fact that natural fibers permit high level of moisture absorption from the surroundings, it can lead to weak bindings and degradation of composite properties. This paper presents an experimental study on the dynamic performance of flax fiber composite beams manufactured at different relative humidity $(\mathrm{RH})$ levels. Five types of flax fiber-reinforced composite materials were made under different $\mathrm{RH}$ values, i.e., dry, 35\%, 50\%, $70 \%$, and $95 \% \mathrm{RH}$, and beam samples were prepared using the composite. Impact hammer testing was conducted to measure the natural frequencies and damping of the beams. It was found that for the first three modes, while the resonant frequencies are very close for most samples, there is a clear drop of frequencies for the composite fabricated at $95 \% \mathrm{RH}$. Along with an increase of the RH level, the damping ratios for all the three modes have reported a slight increase, but the variation is not significant.
\end{abstract}

\begin{abstract}
摘要
开发环境友好型天然纤维复合材料是近年来发展的趋势。然而, 由于天 然纤维允许高水平的水分从周围吸收的事实, 它可以导致弱粘合和复合 性能的劣化。本文研究了在不同相对湿度 $(\mathrm{RH})$ 水平下制备的亚麻纤维 复合材料梁的动态性能。在不同的RH值下制备了五种类型的亚麻纤维增 强复合材料, 即干、35\%、50\%、70\%和 $95 \% \mathrm{RH}$, 并用复合材料制备了梁 试样。冲击锤试验进行了测量的固有频率和阻尼梁。结果发现, 对于前 三种模式, 在大多数样品的共振频率非常接近的情况下, 在 $95 \% R H$ 下制 备的复合材料的频率明显下降。随着RH水平的增加, 所有三种模式的阻 尼比都有轻微的增加, 但变化不显著。
\end{abstract}

\section{KEYWORDS}

Composite material; natural fiber; dynamics; modal testing; relative humidity; flax fiber

\section{关键词}

复合材料; 天然纤维; 动力 学; 模态试验; 相对湿度; 亚麻纤维

\section{Introduction}

A composite is a multiphase material formed by combining two or more dissimilar materials during manufacture to provide an aggregate property that cannot be met by any of its constituent alone (Ashik and Sharma 2015). It offers some advantages including high strength to weight ratio, corrosion resistance, high fatigue strength, etc. Composite materials have been used in many industries for more and more high-technology applications such as in the aerospace, wind turbines, military, automotive, marine and underwater, and even in sports. The development of new biodegradable materials using renewable resources is a recent trend due to the growing concern of environmental issues. For example, natural fiber-reinforced polymer composites have been developed to replace synthetic composites and various traditional materials such as plastic, polymer, or some metals and metal-based alloys (Faruk and 
Sain 2015; Rajesh and Pitchaimani 2017). Researchers all over the world put a significant effort into manufacturing environment-friendly natural fiber composites, which have potential applications in construction, sporting industries, automobile components, and biomedical applications (Goutianos et al. 2006).

Natural fibers are sourced from plants or animals (Gurunathan, Mohanty, and Nayak 2015). The plants produce cellulose fibers held together by the lignin and hemicellulose matrix. These natural fibers include flax, jute, hemp, sisal, ramie, kenaf, coir, and many others (Mallick 2007). Comparing with synthetic fibers, there exist some good properties and superior advantages of natural fibers, such as the relatively low weight, low cost, less damage to processing equipment, good relative mechanical properties such as tensile modulus and flexural modulus, improved surface finish of molded parts composite, renewable resources, easy availability, flexibility during processing, biodegradability, enhanced energy recovery, and minimal health hazards such as reduced dermal and respiratory irritation (Ashik and Sharma 2015; Cristaldi et al. 2010; Dhakal, Zhang, and Richardson 2007; Goutianos et al. 2014; Thakur and Thakur 2014). Composites made with natural fiber reinforcement and corresponding matrix material can be biodegradable, recyclable, and lightweight. Automotive or other machine parts manufactured by natural fibers require less energy to operate (Kalia, Kaith, and Kaur 2009; Summerscales et al. 2010). Even with these advantages, natural fiberreinforced composites have some drawbacks such as high moisture absorption, variability in quality, low strength, and limited durability (Maslinda et al. 2017). In view of it, there are continuous studies required to improve the performance of natural fiber composites.

Among the natural fibers, flax is one of the most widely utilized biofibers (Yan, Chouw, and Jayaraman 2014), and also a widely researched (Nishino 2004; Weclawski and Fan 2013). Flax fibers are produced from the stems of flax bast plant. Flax fibers are cost-effective and offer specific mechanical properties such as a tensile strength in the range of $641 \pm 314$ or $1795 \pm 1127 \mathrm{MPa}$, and Young's modulus of $24 \pm 11$ or $76 \pm 40 \mathrm{GPa}$, with large variability both within studies and between studies (Aslan et al. 2011). As a comparison, the general-purpose boron-containing E-glass fibers have a tensile strength of about 3100-3800 MPa and a Young's modulus of 76-78 GPa (Wallenberger, Watson, and Hong 2001). Composites made of flax fibers with thermoplastic, thermoset, and biodegradable matrices have exhibited good mechanical properties (Yan, Chouw, and Jayaraman 2014). However, the structure of natural fibers permits moisture absorption from the surroundings which causes weak bindings between the fiber and matrix. Like other natural fibers, highly hydrophilic nature of the flax fibers and moisture sensitivity of their composites are the main disadvantages as indicated by some researchers (Celino et al. 2014; Duigou, Davies, and Baley 2013). During manufacturing the composites, sometimes hydrophilic natural fibers and hydrophobic thermoplastic and thermoset matrices require physical and chemical treatments due to their incompatibility. This is required to increase the adhesion between the fiber and the matrix (Dhakal, Zhang, and Richardson 2007; Kalia, Kaith, and Kaur 2009; Yan, Chouw, and Jayaraman 2014). So humidity and water absorption behavior of the natural flax fibers always play a significant role during manufacturing of their bio-composites (Moudood et al. 2017). Several studies reported the effect of moisture content on the properties of natural fiber and their composites (Davies and Bruce 1998; Deng et al. 2010; Dhakal, Zhang, and Richardson 2007; Nilsson 2006; Saidane et al. 2016; Stamboulis et al. 2000; Wang, Sain, and Cooper 2006). Stamboulis et al. (2000) studied the moisture absorption of two types of flax fibers (green and duralin) at different levels of relative humidity (RH). It was found that the moisture content of both green and duralin flax fibers increases with increasing the RH. But the moisture content of green flax is, however, higher than that of duralin flax fibers for all the RH. Nilsson (2006) reported that the moisture content in the fiber has a great influence on the stiffness. Davies and Bruce (1998) investigated the environmental RH on the tensile properties of flax and nettle fibers. It was found that the tensile moduli of flax fibers are dependent on the environmental RH (Davies and Bruce 1998). Both static and dynamic moduli of flax fibers decreased with an increase in RH. The stiffness of the fibers generally increases with decreasing $\mathrm{RH}$, which is in good agreement with the results that the static modulus falls with increasing RH. It is interesting to see that the dynamic modulus is around $12 \mathrm{GPa}$ higher than the static modulus (Davies and Bruce 1998). 
Composite structures are with orthotropic properties caused by the special formation of multiple laminate layers. Due to the complexity of the failure modes of composites comparing with classical materials, engineers have to consider a variety of phenomena during the design to satisfy the demands for performance, safety, and reliability. Since composite structures have been widely used in various high-end engineering applications where sensitivity to structural vibration is a serious concern, studies on the vibrational behavior of composite structures have received considerable attention. However, the anisotropic physical properties of composite beams make the vibration analysis difficult (Liu and Botong 2017). There is no simple approach for dynamic analysis of composite beams considering all kinds of couplings (Hajianmaleki and Qatu 2011). To facilitate engineering analysis and design for the application of composite structures, it is required to understand the dynamic performance and the free vibrations as many vibration-related problems for structures are caused by resonance. The dynamic parameters such as the natural frequencies and damping are of substantial importance. The natural frequency defines how the structure will respond to a dynamic loading, while the damping determines how fast the response of the structure will decay with the time (Yan and Chouw 2014). If the structure is excited at or near one of the modal frequencies, even a small amount of input force can cause a very large vibration response. It is thus dangerous since structural damage due to severe vibration is very likely at resonance. It is important to identify and quantify the resonant frequencies and damping to better understand any structural dynamic problem. Also, for the development of natural fibers-reinforced composite materials in high performance applications, further information about their dynamic properties such as damping is required (Assarar et al. 2015; Berthelot et al. 2008).

For natural fiber-reinforced composite, the dynamic performance is also affected by the water absorption. Mazuki et al. (2011) found that the absorbed water influenced the dynamic mechanical properties of the kenaf fiber-reinforced composites vastly. Yan and Chouw (2014) studied the dynamic and static properties of a flax fiber-reinforced polymer tube confined with coir fiber-reinforced concrete. It was reported that the natural frequency and dynamic modulus of elasticity of the flax fiber-reinforced polymer tube were decreased due to the confinement of plain concrete and carbon fiber-reinforced concrete but the dynamic Poisson's ratio and damping ratio were increased with this confinement. Parhi, Bhattacharyya, and Sinha (2001) analyzed the hygrothermal effects on the dynamic performance for multiple delaminated composite plates and shells. They found that the natural frequencies were decreased but the amplitude of dynamic displacements was increased and stresses were also affected by the higher moisture content and temperature. Saravanos and Hopkins (1995) investigated analytically and experimentally about the effects of delamination on the dynamic characteristics of the composite laminates with damping. They found that composite laminate configuration influenced the delamination effect on the dynamic properties. Natural frequencies were changed with rapid and substantial damping changes but the interfacial friction has no significant effects on it. On the other hand, Adams and Maheri studied the dynamic flexural properties of anisotropic carbon fiber-reinforced plastic and glass-reinforced plastic composite beams (Cawley and Adams 1979). Inconsistency could be caused between the measured and predicted effective flexural moduli of the beams by the anisotropy of the composites. It was occurred by the high aspect ratio which can make the deformation insignificant during the simple bending of the beams.

Despite the practical importance of the dynamic performance of biofiber composite materials, the published research work in this field is scarce, especially on the influence of relative humility in the manufacturing process. Limited research is available to address the vibration behavior of flax fiber composite material. In view of the demand, this research aims to investigate the dynamic behavior of flax fiber composite beams to understand the influence of the humility on the vibration frequency and damping. 


\section{Material and experiments}

\section{Material preparation}

Commercially available unidirectional flax fabric supplied by Lineo, France, with a surface density of $180 \mathrm{~g} /$ $\mathrm{m}^{2}$, and R-180 Part-A epoxy resin (from Nuplex industries (Aust) Pty Ltd., Australia), was used to fabricate the flax fiber-reinforced composite materials. The matrix was mixed with H180 standard hardener (from Nuplex, Australia) before infusion. TR 102 regular wax (from Nuplex, Australia) was used to release the mold. The fabric, stored in an environment condition of $65 \% \mathrm{RH}$ and $23^{\circ} \mathrm{C}$, was cut into rectangular pieces $(230 \mathrm{~mm} \times 270 \mathrm{~mm})$, weighed, and placed inside a TD300F dehumidifier oven (Thermoline Scientific) at $60^{\circ} \mathrm{C}$ to make it dry. The weight loss was monitored every $20 \mathrm{~min}$ until equilibrium was reached.

In order to assess the influence of the moisture content on the performance of the material, composite samples were made according to a number of RH levels, including dry, 35\%, 50\%, 70\%, and 95\% RH. The $\mathrm{RH}$ levels of the fabrics were achieved using a model CH700V Angelantoni humidity chamber. The composites were manufactured by the vacuum-assisted resin infusion technique using 10 layers of unidirectional flax fiber fabric, which were conditioned at $25^{\circ} \mathrm{C}$ at different $\mathrm{RH}$ levels in the humidity chamber $(35 \%, 50 \%, 70 \%, 95 \% \mathrm{RH})$. To guarantee that the composites were prepared with the correct moisture content in the fabrics, the following procedures were carried out:

- Cut the fabric layers to needed dimensions $(230 \mathrm{~mm} \times 270 \mathrm{~mm})$ and dry them inside the dehumidifier oven;

- Place the fabric layers inside the humidity chamber at the desired value of RH for $24 \mathrm{~h}$.

- Wax an aluminum flat mold and prepared all the infusion materials (bag, peel ply, flow media, hoses) to the correct dimensions.

- Withdraw the fabrics from the humidity chamber and quickly place them on the aluminum mold.

- Lay the peel ply and the flow media over the fabrics and seal the vacuum bag to the mold at two sides, attach the hoses (resin and vacuum ports) also there. In this way, the other two longer sides of the bag remain widely open. It should be noted that although this procedure takes no more than $15 \mathrm{~min}$, the fabrics can lose or gain moisture, depending on the moisture gradient between the fabrics and the environment.

- Place the mold inside the humidity chamber at the desired RH level for another $24 \mathrm{~h}$, for the fabrics to reach the corresponding equilibrium value for the set $\mathrm{RH}$.

- Remove the mold from the humidity chamber and seal the two open sides instantaneously (in less than $1 \mathrm{~min}$ ), to ensuring that the fabrics are kept at the desired moisture content.

- Carry out the resin infusion immediately with a vacuum pump and at room temperature. The pressure is $-100 \mathrm{kPa}$. Time for each infusion is between 10 and $15 \mathrm{~min}$.

- In addition, composites using dry fabrics were also made. In this case, fabrics were dried in the oven for $4 \mathrm{~h}$ at $60^{\circ} \mathrm{C}$ and then placed in the mold, the infusion set-up was prepared and the vacuum bag was completely sealed to the mold. Vacuum was applied and the stack of fabrics was dried in the oven for another $3 \mathrm{~h}$ under full vacuum at $45^{\circ} \mathrm{C}$. Since the preform was under vacuum and there was no risk of moisture absorption, the resin was infused $15 \mathrm{~min}$ after the mold was withdrawn from the oven, allowing the system to cool down and reach the room temperature.

- All composites were cured under full vacuum at room temperature for $24 \mathrm{~h}$ and then post cured for $8 \mathrm{~h}$ at $60^{\circ} \mathrm{C}$. The resultant thickness of the composite panels was around $3 \mathrm{~mm}$. Beam samples with a nominal dimension of $250 \mathrm{~mm} \times 25 \mathrm{~mm} \times 3 \mathrm{~mm}$, as shown in Figure 1, were prepared from the composite panels by means of a TROTEC Speedy 300 laser cutting machine to the required shape and dimensions, with three samples for each material group. On each type of beam sample, the thickness was measured using a Vernier on eight different locations. The resultant average thickness of each type of beam sample and the standard deviation (SD) 


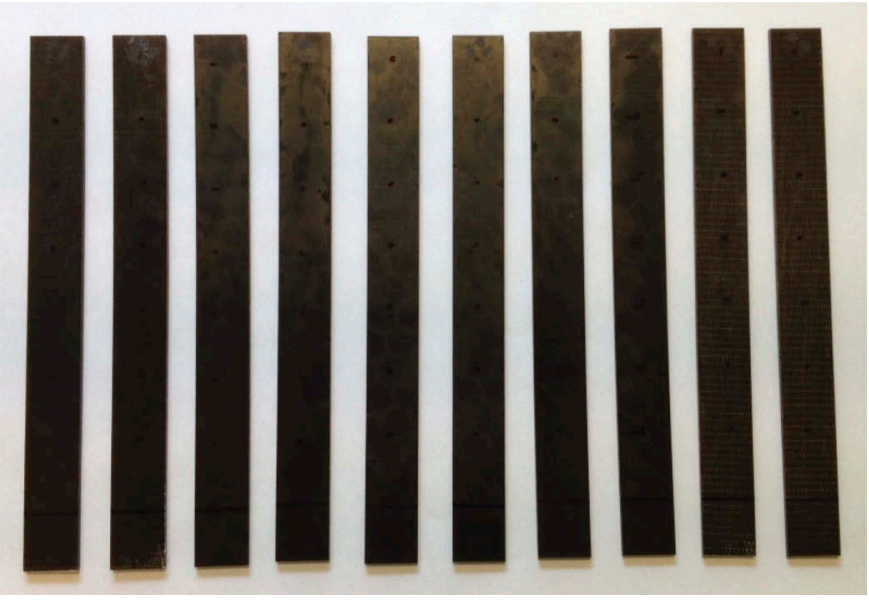

Figure 1. Composite beam samples.

Table 1. Resultant average thickness of each type of beam sample and the standard deviation on this measurement.

\begin{tabular}{lccc}
\hline Material & Thickness $(\mathrm{mm})$ & Standard deviation & Fiber volume fraction (\%) \\
\hline C-D (Dry) & 3.004 & 0.029 & 38.9 \\
C-35 (35\% RH) & 3.045 & 0.029 & 38.4 \\
C-50 (50\% RH) & 2.986 & 0.016 & 39.1 \\
C-70 (70\% RH) & 3.011 & 0.039 & 38.8 \\
C-95 (95\% RH) & 2.951 & 0.045 & 39.6 \\
\hline
\end{tabular}

on this measurement are listed in Table 1. The fiber volume fraction for each type of composite is also listed in Table 1, which was determined by using the following equation:

$$
\text { fiber volume fraction }=\frac{\left(\text { number of fabric layers }{ }^{\times} \text {areal weight of the flax fabric }\right)}{\left(\text { fiber density }{ }^{\times} \text {composite thickness }\right)}
$$

In this study, the number of fabric layers is 10 , the areal weight of the flax fabric is $180 \mathrm{~g} / \mathrm{m}^{2}$, the fiber density of flax is taken as $1.54 \mathrm{~g} / \mathrm{cm}^{3}$ (Amiri et al. 2017), and the composite thickness used is as listed in Table 1. The variation of moisture in the composite was taken into account in the calculation by using the specific composite thickness values. It can be seen that an average fiber volume fraction is about $39 \%$, and the value for each sample is quite close. The SD is $0.45 \%$. The influence of RH values on the fiber volume fraction is thus not too significant.

In summary, five types of flax fiber-reinforced composite materials were prepared under different $\mathrm{RH}$ values, i.e., dry, 35\%, 50\%, 70\%, and 95\% RH. Accordingly, the composite samples made under these RH conditions are referred to as C-D, C-35, C-50, C-70, and C-95 in this study. In a previous study (Moudood et al. 2017), the authors have investigated the effect of moisture in flax fibers on the overall quality of epoxy/ flax biocomposites, especially on some basic mechanical properties such as the stiffness in terms of Young's modulus and flexural modulus, fracture strain, tensile strength and flexural strength, etc. Microstructural analysis was also done by using optical microscopy and SEM, and it was found that highly humid fabrics (95\% RH) generate post-processing deformation of finished parts and also lead to poor microstructural quality such as voids and matric cracks. The current study can be considered as an extension of the previous article, with a focus on the dynamic testing with different humidified flax fiber composites. 


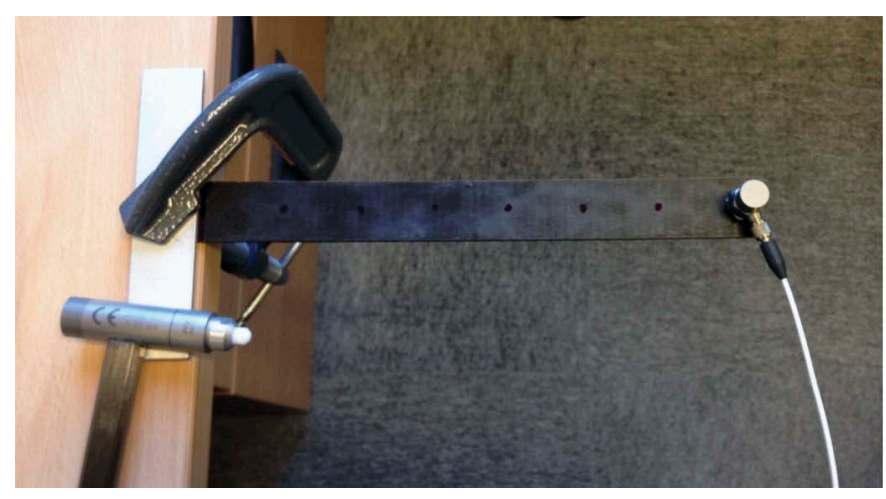

Figure 2. Setup of the impact hammer testing.

\section{Hammer testing}

Impact hammer testing was conducted to identify the dynamic properties of the composite beams. It is a fast and convenient approach to determine the modal properties of structures. The dynamic parameters including the natural frequencies, modal damping ratios, and mode shapes of a test structure can be identified from the hammer testing. A PCB Piezotronics model 086C03 ICP instrumented hammer was used to impact the beam under test. A medium impact tip (white plastic) was selected; thus, the beam samples can be excited over a medium frequency range up to nearly $1000 \mathrm{~Hz}$ (within $-3 \mathrm{~dB}$ ). The impact force was measured by the embedded ICP quartz force sensor mounted on the striking end of the impact hammer. A PCB model 352C33 piezoelectric ICP accelerometer was mounted on the free end of the cantilever beam to measure the vibration response of the structure upon the hammer impact. Adhesive mounting with bee wax was employed to form temporary installation on the beam. A Prosig P8004 data acquisition system and DATS software were used for data acquisition and signal processing of the impact hammer testing. The resultant frequency response function (FRF) was an inertance calculated in terms of the frequency response of the acceleration relative to the excitation force. In the testing, it is assumed that the measured inertance at any point on a structure can be represented mathematically as a summation of the individual modal inertance contributions from all the modes present in the analysis bandwidth.

The flax fiber composite beams were clamped at one end onto a desk with a C-clamp to form a cantilever beam. The overhang length of the cantilever was $225 \mathrm{~mm}$. Seven node points were selected on the beam to carry out rover hammer impact testing, with an equal space of about $30 \mathrm{~mm}$. The accelerometer was mounted on the first node which was close to the tip of the cantilever beam. A photo of the experimental setup is shown in Figure 2. On each node point, the hammer impact testing was conducted for three times and an average of the FRF was obtained by the DATS Impact Hammer module to remove random noise. In such a way, a set of FRFs of the structure was measured. For each beam sample, three sets of hammer testing were conducted. Since there were three beam samples prepared for each type of material, there were nine sets of hammer testing data for each type of composite. The mean values and SDs of key modal parameters were obtained to make the results statistically reliable.

\section{Results and discussions}

As a continuous structure, a beam sample has an infinite number of degrees of freedom, which means there are an infinite number of modes. But in reality, it is possible to measure only a small subset of the FRFs on a structure via modal testing. In this study, only seven node points were selected to measure the FRFs. From this small subset of FRFs, the modes within the frequency range of the measurements can still be accurately determined. Modal parameters were then identified by 


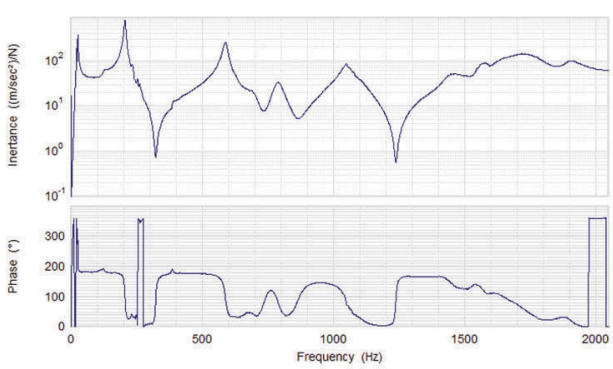

(a)

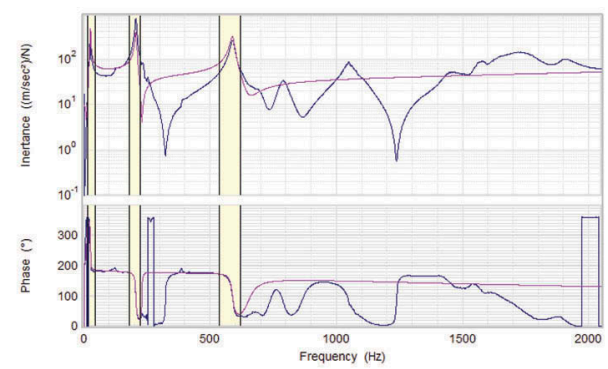

(b)

Figure 3. Example of (a) measured and (b) fitted frequency response functions.

curve fitting a set of FRFs for a beam sample. A typical FRF is shown in Figure 3. From the FRF curve, the major resonant frequencies can be identified, the corresponding damping ratios can be calculated, and the mode shape at each mode can be determined through curve fitting. In this study, only the first three modes were analyzed. The frequency bands around the first three significant modes (peaks) were selected, and multiple degrees of freedom option was used for the analysis and curve fitting. Figure 3(b) shows an example of the analysis results with the fitted FRF superimposed on top of the measured FRF. The identified modal parameters including the mean natural frequencies and damping ratios for the first three modes, and the corresponding SD as well, are summarized in Table 2 for all the five types of composite materials with different $\mathrm{RH}$ levels. The variations of the measured first three mean natural frequencies of the beams versus $\mathrm{RH}$ values are also illustrated in Figure 4, while the variations of the corresponding damping ratios are shown in Figure 5.

Table 2. Key modal parameters identified from the hammer testing for the (a) first mode, (b) second mode, and (c) third mode.

\begin{tabular}{|c|c|c|c|c|}
\hline \multicolumn{5}{|l|}{ (a) } \\
\hline \multirow[b]{2}{*}{ Material } & \multicolumn{2}{|c|}{ 1st mode: frequency $(\mathrm{Hz})$} & \multicolumn{2}{|c|}{ 1st mode: damping(\%) } \\
\hline & Mean & SD & Mean & SD \\
\hline C-D (Dry) & 25.2 & 0.338 & 1.91 & 0.297 \\
\hline $\mathrm{C}-35(35 \% \mathrm{RH})$ & 25.5 & 0.159 & 1.99 & 0.302 \\
\hline $\mathrm{C}-50(50 \% \mathrm{RH})$ & 25.1 & 0.139 & 1.97 & 0.638 \\
\hline C-70 (70\% RH) & 25.2 & 0.448 & 2.32 & 0.684 \\
\hline C-95 (95\% RH) & 24.8 & 0.700 & 2.08 & 0.339 \\
\hline \multicolumn{5}{|l|}{ (b) } \\
\hline & \multicolumn{2}{|c|}{ 2nd mode: frequency $(\mathrm{Hz})$} & \multicolumn{2}{|c|}{ 2nd mode: damping(\%) } \\
\hline Material & Mean & SD & Mean & SD \\
\hline C-D (Dry) & 204.8 & 2.539 & 1.23 & 0.181 \\
\hline $\mathrm{C}-35(35 \% \mathrm{RH})$ & 208.1 & 0.782 & 1.51 & 0.220 \\
\hline $\mathrm{C}-50(50 \% \mathrm{RH})$ & 203.1 & 0.928 & 1.54 & 0.070 \\
\hline C-70 (70\% RH) & 203.3 & 1.803 & 1.49 & 0.102 \\
\hline C-95 (95\% RH) & 200.8 & 7.049 & 1.56 & 0.514 \\
\hline \multicolumn{5}{|l|}{ (c) } \\
\hline & \multicolumn{2}{|c|}{ 3rd mode: frequency $(\mathrm{Hz})$} & \multicolumn{2}{|c|}{ 3rd mode: damping(\%) } \\
\hline Material & Mean & SD & Mean & SD \\
\hline C-D (Dry) & 574.8 & 1.91 & 1.24 & 0.362 \\
\hline $\mathrm{C}-35(35 \% \mathrm{RH})$ & 589.0 & 1.99 & 1.31 & 0.245 \\
\hline $\mathrm{C}-50(50 \% \mathrm{RH})$ & 572.3 & 1.97 & 1.28 & 0.242 \\
\hline $\mathrm{C}-70(70 \% \mathrm{RH})$ & 573.3 & 2.32 & 1.19 & 0.145 \\
\hline C-95 (95\% RH) & 566.7 & 2.08 & 1.37 & 0.366 \\
\hline
\end{tabular}

Both the mean values and the standard deviations (SD) are listed. 


\section{First Mode}

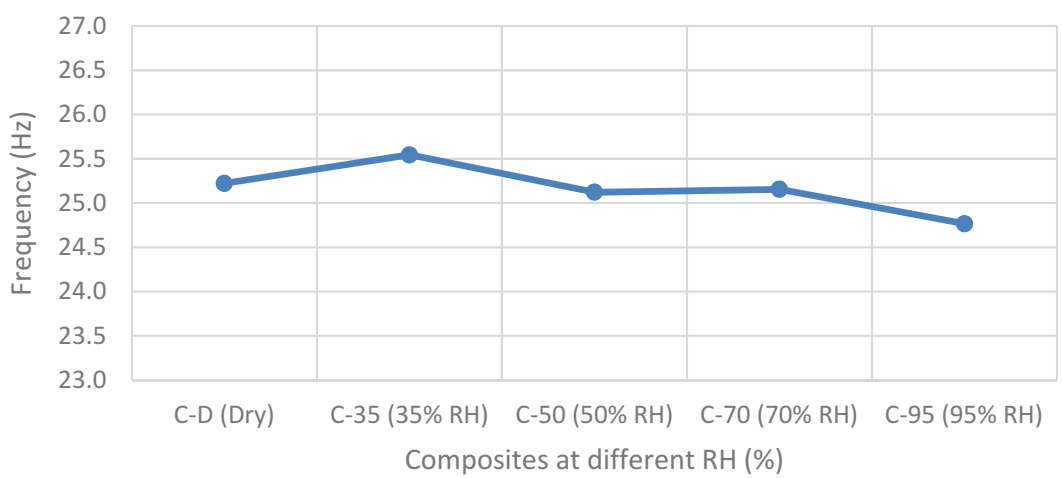

\section{Second Mode}

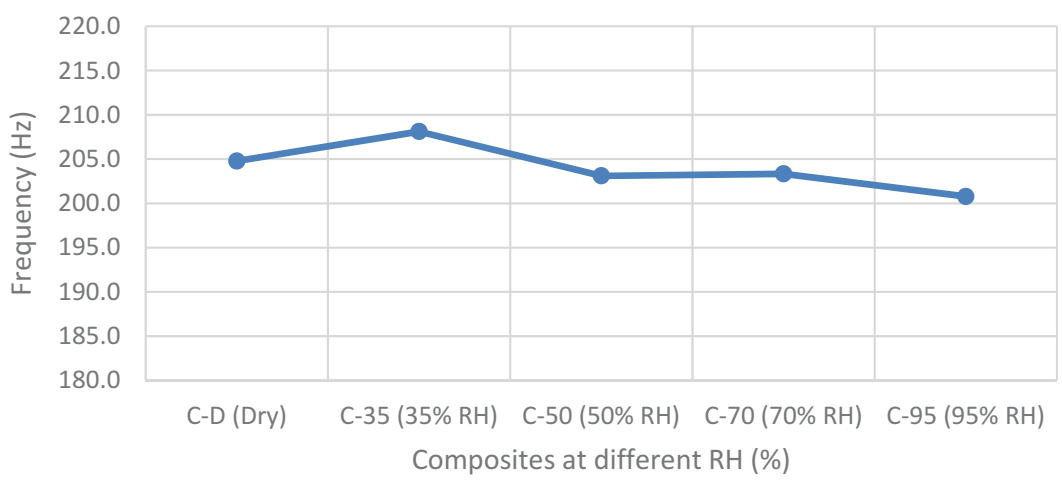

\section{Third Mode}

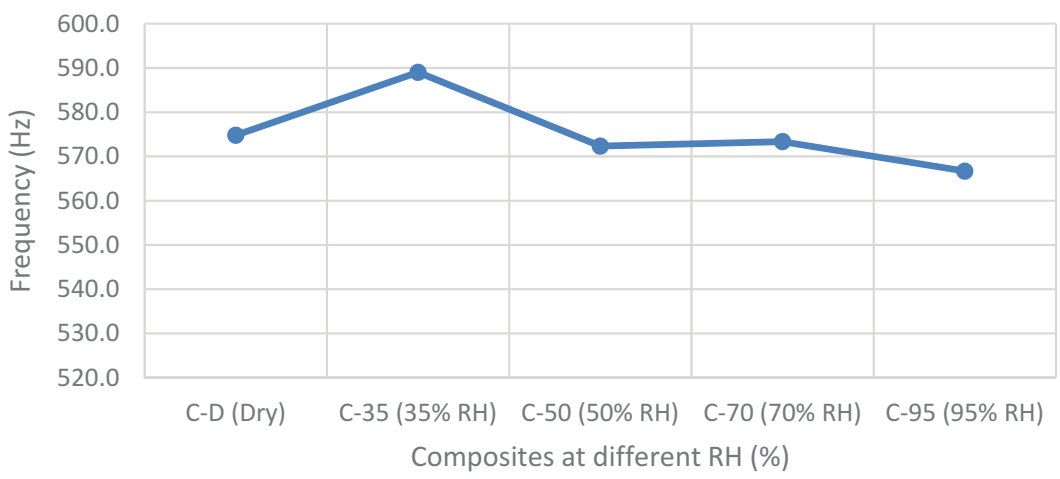

Figure 4. Variation of the measured first three resonant frequencies (mean) of the beams versus RH values.

It can be seen from the modal results that for the composite manufactured under dry condition (CD), the first three natural frequencies are 25.2, 204.8, and $574.8 \mathrm{~Hz}$, respectively. For the composite samples manufactured under 35\% RH (C-35), 50\% RH (C-50), and 70\% RH (C-70) conditions, the 


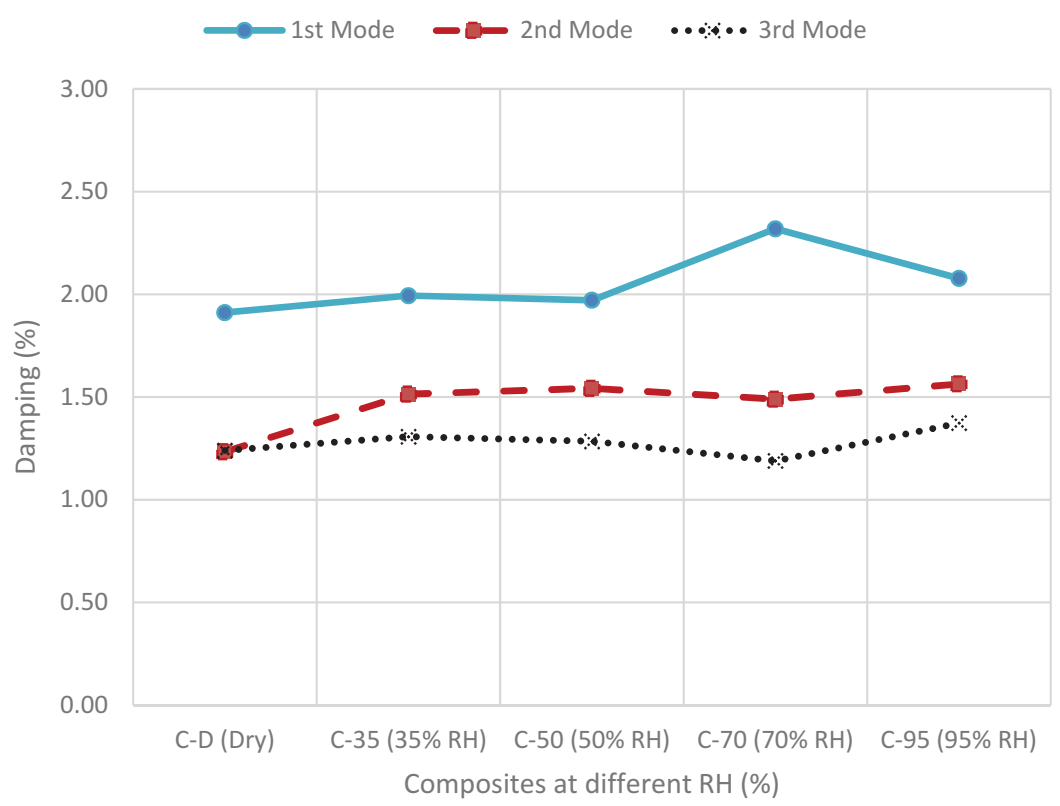

Figure 5. Variation of the measured first three damping ratios (mean) of the beams versus RH values.

resonant frequencies are also quite close. As to the composite fabricated under the condition of $95 \% \mathrm{RH}$ (C-95), there is a clear drop of all the three resonant frequencies. Actually, the densities of all the five types of composite samples are almost the same, but with the increment of the RH value, the flexural modulus of the composite drop, which is listed in Table 3. For the C-95 composite, the drop of the flexural modulus is relatively significant. Such a drop of the flexural modulus could be the main reason for the decline of the resonant frequencies for the C-95 material. It is interesting to note that for the modal damping, along with an increase of the $\mathrm{RH}$ level, the damping ratios for all the three modes show a slight increasing trend, but the variation is not significant. For the first mode, the damping ratios are close to $2 \%$, and for the higher modes, a drop of the damping ratios was observed. This phenomenon indicates that all the materials have slightly better damping at the first resonant frequency. There is no significant difference in terms of damping properties for all the materials used.

It should be noted that in the hammer testing process, the vibration response of the cantilever beam was measured by using an accelerometer attached to near the tip of the beam. Such a measurement setup inevitably added an extra mass to the beam tip and affected the measurement results. Specifically, the modal frequencies of the beam were influenced. A mass loading on the beam would result in a lower value for a modal frequency. Therefore, to obtain an accurate set of modal parameters, the mass loading effect should be eliminated mathematically or by using noncontact vibration measurement sensors such as a laser Doppler vibrometer. Nevertheless, since the same accelerometer was used for the hammer testing for all the beam samples in a similar configuration, for the purpose to assess the influence of the HR level during manufacturing on the dynamic performance of composite materials, qualitatively the relative comparison between different samples

Table 3. Density and flexural modulus of elasticity of the composites.

\begin{tabular}{lcc}
\hline Material & Density $(\mathrm{gm} / \mathrm{cc})$ & Flexural modulus (GPa) \\
\hline C-D (Dry) & 1.225 & 16.2 \\
C-35 (35\% RH) & 1.262 & 15.96 \\
C-50 (50\% RH) & 1.265 & 15.71 \\
C-70 (70\% RH) & 1.264 & 15.18 \\
C-95 (95\% RH) & 1.255 & 11.81 \\
\hline
\end{tabular}


is believed to be still unaffected in terms of a general trend. Further, attachment of an accelerometer on the beam sample should not bring up noticeable change to the damping. Therefore, the conclusions from the experimental results should be trustable.

\section{Conclusions}

The following conclusions can be drawn from this study:

- Natural fiber-reinforced composites have been developed as new biodegradable materials to replace synthetic composites and various traditional materials. However, high moisture absorption is a drawback which influences the mechanical property and dynamic performance of the composite.

- Flax fiber-reinforced composite materials were fabricated by using unidirectional flax fabric and epoxy resin through infusion. The composites were made under five different $\mathrm{RH}$ values, i.e., dry, $35 \%, 50 \%, 70 \%$, and $95 \% \mathrm{RH}$. Beam samples were prepared using the composite panels.

- Impact hammer testing was conducted to measure the natural frequencies and damping of the beams. Cantilever beams were formed by clamping the composite beams at one end. Modal parameters were identified by curve fitting a set of measured FRFs.

- It was found that for the first three modes, while the resonant frequencies are very close for most samples, there is a clear drop of frequencies for the composite fabricated at $95 \% \mathrm{RH}(\mathrm{C}$ 95). Along with an increase of the RH level, the damping ratios for all the three modes have reported a slight increase, but the variation is not significant.

\section{ORCID}

Huaizhong Li (D) http://orcid.org/0000-0002-5617-702X

\section{References}

Amiri, A., Z. Triplett, A. Moreira, N. Brezinka, M. Alcock, and C. A. Ulven. 2017. Standard density measurement method development for flax fiber. Industrial Crops and Products 96:196-202. Elsevier B.V. doi:10.1016/j. indcrop.2016.11.060.

Ashik, K. P., and R. S. Sharma. 2015. A review on mechanical properties of natural fiber reinforced hybrid polymer composites. Journal of Minerals and Materials Characterization and Engineering 3 (September):420-26. doi:10.4236/ jmmce.2015.35044.

Aslan, M., G. Chinga-Carrasco, B. F. Sørensen, and B. Madsen. 2011. Strength variability of single flax fibres. Journal of Materials Science 46 (19):6344-54. doi:10.1007/s10853-011-5581-x.

Assarar, M., W. Zouari, H. Sabhi, R. Ayad, and J. M. Berthelot. 2015. Evaluation of the damping of hybrid carbon-flax reinforced composites. Composite Structures 132:148-54. Elsevier Ltd. doi:10.1016/j.compstruct.2015.05.016.

Berthelot, J.-M., M. Assarar, Y. Sefrani, and A. E. Mahi. 2008. Damping analysis of composite materials and structures. Composite Structures 85 (3):189-204. doi:10.1016/j.compstruct.2007.10.024.

Cawley, P., and R. D. Adams. 1979. A vibration technique for non-destructive testing of fibre composite structures. 161-75.

Celino, A., S. Freour, F. Jacquemin, and P. Casari. 2014. The hygroscopic behavior of plant fibers: A review. Frontiers in Chemistry 2 (1):43.UNSP 4310.3389/fchem.2013.00043.

Cristaldi, G., A. Latteri, G. Recca, and G. Cicala. 2010. Composites Based on Natural Fibre Fabrics, in Woven Fabric Engineering, Polona Dobnik Dubrovski (Ed.), ISBN: 978-953-307-194-7, InTech, 317-42. Available from: http:// www.intechopen.com/books/woven-fabric-engineering/composites-based-on-naturalfibre-fabrics

Davies, G. C., and D. M. Bruce. 1998. Effect of environmental relative humidity and damage on the tensile properties of flax and nettle fibers. Textile Research Journal 68 (9):623-29. doi:10.1177/004051759806800901.

Deng, H., C. T. Reynolds, N. O. Cabrera, N. M. Barkoula, B. Alcock, and T. Peijs. 2010. The water absorption behaviour of all-polypropylene composites and its effect on mechanical properties. Composites Part B-Engineering 41 (4):268-75. doi:10.1016/j.compositesb.2010.02.007.

Dhakal, H. N., Z. Y. Zhang, and M. O. W. Richardson. 2007. Effect of water absorption on the mechanical properties of hemp fibre reinforced unsaturated polyester composites. Composites Science and Technology 67 (7-8):1674-83. doi:10.1016/j.compscitech.2006.06.019. 
Duigou, A. L., P. Davies, and C. Baley. 2013. Exploring durability of interfaces in flax fibre/epoxy micro-composites. Composites Part A-Applied Science and Manufacturing 48:121-28. doi:10.1016/j.compositesa.2013.01.010.

Faruk, O., and M. Sain. 2015. Biofiber reinforcement in composite materials. O. Faruk, and M. Sain, Edited by. Elsevier Ltd., Cambridge, UK. doi:10.1016/B978-1-78242-122-1.50028-9

Goutianos, S., R. Arévalo, B. F. Sørensen, and T. Peijs. 2014. Effect of processing conditions on fracture resistance and cohesive laws of binderfree all-cellulose composites. Applied Composite Materials 21 (6):805-25. doi:10.1007/ s10443-013-9381-0.

Goutianos, S., T. Peijs, B. Nystrom, and M. Skrifvars. 2006. Development of flax fibre based textile reinforcements for composite applications. Applied Composite Materials 13 (4):199-215. doi:10.1007/s10443-006-9010-2.

Gurunathan, T., S. Mohanty, and S. K. Nayak. 2015. A review of the recent developments in biocomposites based on natural fibres and their application perspectives. Composites Part A: Applied Science and Manufacturing 77:1-25. Elsevier Ltd. doi:10.1016/j.compositesa.2015.06.007.

Hajianmaleki, M., and M. S. Qatu. 2011. Mechanics of composite beams. Advances in Composite Materials - Analysis of Natural and Man- Made Materials 527-46. doi:10.1017/CBO9780511547140.

Kalia, S., B. S. Kaith, and I. Kaur. 2009. Pretreatments of natural fibers and their application as reinforcing material in polymer composites-A review. Polymer Engineering and Science 49 (7):1253-72. doi:10.1002/pen.21328.

Liu, C.-S., and L. Botong. 2017. An upper bound theory to approximate the natural frequencies and parameters identification of composite beams. Composite Structures 171:131-44. Elsevier Ltd. doi:10.1016/j.compstruct.2017.03.014.

Mallick, P. K. 2007. Fiber-reinforced composites: materials, manufacturing, and design. mechanical engineering, 3rd ed. Boca Raton, FL: CRC Press. doi: 10.3144/expresspolymlett.2007.115.

Maslinda, A. B., M. S. Abdul Majid, M. J. M. Ridzuan, M. Afendi, and A. G. Gibson. 2017. Effect of water absorption on the mechanical properties of hybrid interwoven cellulosic-cellulosic fibre reinforced epoxy composites. Composite Structures 167:227-37. doi:10.1016/j.compstruct.2017.02.023.

Mazuki, A. A. M., H. M. Akil, S. Safiee, Z. A. M. Ishak, and A. Abu Bakar. 2011. Degradation of dynamic mechanical properties of pultruded kenaf fiber reinforced composites after immersion in various solutions. Composites Part B-Engineering 42 (1):71-76. doi:10.1016/j.compositesb.2010.08.004.

Moudood, A., W. Hall, A. Öchsner, L. Huaizhong, A. Rahman, and G. Francucci. 2017. Effect of moisture in flax fibres on the quality of their composites. Journal of Natural Fibers 00(00):1-16. Taylor \& Francis. doi:10.1080/ 15440478.2017.1414651.

Nilsson, T. 2006. "Micromechanical modelling of natural fibres for composite materials." Lund University.

Nishino, T. 2004. Natural fibre sources. In Green composites: polymer composites and the environment, ed. C. Baillie, 49-80. Cambridge, UK: Woodhead Publishing. doi: 10.1016/B978-1-85573-739-6.50007-5.

Parhi, P. K., S. K. Bhattacharyya, and P. K. Sinha. 2001. Hygrothermal effects on the dynamic behavior of multiple delaminated composite plates and shells. Journal of Sound and Vibration 248 (2):195-214. doi:10.1006/jsvi.2000.3506.

Rajesh, M., and J. Pitchaimani. 2017. Experimental investigation on buckling and free vibration behavior of woven natural fiber fabric composite under axial compression. Composite Structures 163:302-11. Elsevier Ltd. doi:10.1016/ j.compstruct.2016.12.046.

Saidane, E., D. Scida, M. Assarar, and R. Ayad. 2016. Assessment of 3D moisture diffusion parameters on flax/epoxy composites. Composites Part A-Applied Science and Manufacturing 80:53-60. doi:10.1016/j.compositesa.2015.10.008.

Saravanos, D. A., and D. A. Hopkins. 1995. "Effects of Delaminations on the Damped Dynamic Characteristics of Composite Laminates: Mechanics and Experiments."

Stamboulis, A., C. A. Baillie, S. K. Garkhail, H. G. H. Van Melick, and T. Peijs. 2000. Environmental durability of flax fibres and their composites based on polypropylene matrix. Applied Composite Materials 7 (5-6):273-94. doi:10.1023/A:1026581922221.

Summerscales, J., N. Dissanayake, A. Virk, and W. Hall. 2010. A review of bast fibres and their composites. Part 2composites. Composites Part A-Applied Science and Manufacturing 41 (10):1336-44. doi:10.1016/j. compositesa.2010.05.020.

Thakur, V. K., and M. K. Thakur. 2014. Processing and characterization of natural cellulose fibers/thermoset polymer composites. Carbohydrate Polymers 109:102-17. doi:10.1016/j.carbpol.2014.03.039.

Wallenberger, F. T., J. C. Watson, and L. Hong. 2001. Glass fibers. ASM Hanbook 21 (Ref 19):27-34. doi:10.1361/ asmhba0003353.

Wang, W., M. Sain, and P. A. Cooper. 2006. Study of moisture absorption in natural fiber plastic composites. Composites Science and Technology 66 (3-4):379-86. doi:10.1016/j.compscitech.2005.07.027.

Weclawski, B. T., and M. Fan. 2013. Bast fibers composites for engineering structural applications. In Green composites from natural resources, edited by Vijay Kumar Thakur, Boca Raton, FL: CRC Press, 133.

Yan, L., N. Chouw, and K. Jayaraman. 2014. Flax fibre and its composites - A review. Composites Part B: Engineering 56:296-317. Elsevier Ltd. doi:10.1016/j.compositesb.2013.08.014.

Yan, L. B., and N. Chouw. 2014. Dynamic and static properties of flax fibre reinforced polymer tube confined coir fibre reinforced concrete. Journal of Composite Materials 48 (13):1595-610. doi:10.1177/0021998313488154. 


\title{
On the Dynamic Performance of Flax Fiber Composite Beams Manufactured at Different Relative Humidity Levels
}

\author{
Huaizhong Li, Abdul Moudood, Wayne Hall, Gaston Francucci \& Andreas \\ Öchsner
}

To cite this article: Huaizhong Li, Abdul Moudood, Wayne Hall, Gaston Francucci \& Andreas Öchsner (2018): On the Dynamic Performance of Flax Fiber Composite Beams Manufactured at Different Relative Humidity Levels, Journal of Natural Fibers, DOI: 10.1080/15440478.2018.1507864

To link to this article: https://doi.org/10.1080/15440478.2018.1507864

Published online: 23 Aug 2018.

Submit your article to this journal $₫$

View Crossmark data $\nearrow$ 